\title{
Management of Rectal Injury during Laparoscopic Radical Prostatectomy
}

\author{
Octavio A. Castillo, Elias Bodden, Gonzalo Vitagliano \\ Section of Endourology and Laparoscopic Urology, Department of Urology, Clinica Santa Maria \\ and Department of Urology, School of Medicine, Universidad de Chile, Santiago de Chile, Chile
}

\begin{abstract}
Purpose: Because laparoscopic radical prostatectomy remains a challenging procedure, rectal injury is always a potential complication. We review the incidence of rectal injuries at our institution in the first 110 consecutive laparoscopic extraperitoneal radical prostatectomies.

Materials and Methods: Nine (8\%) out of the first 110 laparoscopic extraperitoneal radical prostatectomies performed between December 2001 and February 2004, were complicated by rectal injury. Mean patient age was 64.9 years (range 52 to 74) and mean prostate specific antigen was $11.45 \mathrm{ng} / \mathrm{mL}$ (range 4.8 to 37.4). Median preoperative Gleason score was 6 (range 4 to 8) and clinical stage was T1c, T2a, T2b in 6, 2 and 1 patient, respectively. Mean operative time was 228 minutes (range 150 to 300 ).

Results: From 9 injuries, 6 were diagnosed and repaired intraoperatively and 3 were diagnosed postoperatively. From the 6 cases of intraoperative diagnosis and repair, 3 patients healed primarily without colostomy and a recto-urinary fistula was evidenced by pneumaturia in the remaining three. These 3 patients were managed conservatively with urethral catheterization during 30 days. One of the patients required secondary fistula repair by anterior transphincteric, transanal surgical approach (ASTRA). Urinary fistula was diagnosed postoperatively on 3 patients. A diverting colostomy was performed on one patient with secondary fistula repair by ASTRA. Another patient required laparotomy due to peritonitis and urinary fistula was later managed with ASTRA. On the third patient conservative management with urethral catheter was successful. All fistulas repaired with ASTRA evolved uneventfully. There was no perioperative mortality.

Conclusions: Rectal injury during laparoscopic radical prostatectomy can be managed intraoperatively or by a minimally invasive procedure without the need of colostomy. Laparoscopic radical prostatectomy is a challenging procedure and is associated with a very flat learning curve; the incidence of rectal injuries is prone to diminish with experience.
\end{abstract}

Key words: prostatic neoplasms; prostatectomy; laparoscopy; injuries; rectum

Int Braz J Urol. 2006; 32: 428-33

\section{INTRODUCTION}

The first laparoscopic transperitoneal radical prostatectomy was described by Schuessler in 1992 (1). After that, Raboy made the first extraperitoneal attempts of this technique (2). It was not until the report of Bollens' work in 2001 that a series of pure extraperitoneal laparoscopic prostatectomies was published (3). Perfect anatomic knowledge and laparoscopic expertise are needed for this very challenging technique.

According to world literature, rectal injury is a potential complication of radical retropubic prostatectomy with an incidence of 0.5 to 9\% (4-9).

Mastering of laparoscopic radical prostatectomy takes time, the majority of rectal lesions 
occur during the learning curve of this technique. The transperitoneal approach is not exempt of rectal injuries. When this approach is preferred, visceral complications may be associated. Guillonneau in his series reported a $1.8 \%$ of complications specifically related to the transperitoneal approach. We review the management of rectal injury in 110 consecutive laparoscopic radical prostatectomies performed by the same surgeon at our institution.

\section{MATERIALS AND METHODS}

Nine $(8 \%)$ out of the first 110 laparoscopic extraperitoneal radical prostatectomies performed between December 2001 and November 2003, were complicated by rectal injury. From the 9 injuries, 7 $(77.8 \%)$ were observed in the first 50 patients (cases $\# 4,6,7,18,22,26,28)$, and 2 were diagnosed in the later 50 (cases \# 67, 79). Mean patient age was 64.9 years (range 52 to 74) and mean prostate specific antigen was $11.45 \mathrm{ng} / \mathrm{mL}$ (range 4.8 to 37.4 ). Median preoperative Gleason score was 6 (range 4 to 8 ) and clinical stage was T1c, T2a, T2b in 6, 2 and 1 patient, respectively.

The American Society of Anesthesiology score (ASA) was I in 6 patients and II in 3 patients. Only 2 patients had history of abdominal surgery and 1 of them history of TURP. Five out of 9 patients had a body mass index (BMI) greater than 25 . Neoadjuvant hormone therapy was administered in one patient. Patient characteristics are summarized on Table-1.

The patients were given one dose of a secondgeneration cephalosporin preoperatively and a fosfosoda enema was administered. Six hours after surgery a $40 \mathrm{mg}$ subcutaneous dose of enoxaparin was administered and continued on daily basis until the patient was discharged. Mean operative time was 228 minutes (range 150 to 300 ).

Digital rectal examination is routinely performed after the prostate has been removed and before the beginning of the anastomosis (at the beginning of the series digital rectal examination was only done if a rectal lesion was suspected, this practice was abandoned due to the fact that two rectal lesions were intraoperatively missed). If a lesion on the rectal wall is identified, repair of the defect in 2 layers is performed. The mucosa and seromuscular layers are closed with a 2-zero monocryl running suture with particular attention to the edges of the defect. A second layer including the tissue over the neurovascular bundles is sutured with interrupted 2-zero monocryl sutures. The integrity of the repair is controlled by abundantly washing the operative field with saline and introducing a $30 \mathrm{Fr}$ multiperforated rubber catheter through the rectum; then air is insufflated while checking for bubbles in the saline filled pelvic cavity. The vesicourethral anastomosis is performed with interrupted sutures of 2-zero monocryl. The watertightness of the anastomosis is confirmed after placing a urethral catheter and filling the bladder with $200 \mathrm{cc}$ of saline. If necessary additional stitches are made until a watertight anastomosis is obtained. Digital anal dilation is performed and a suction tube is left in the Retzius space.

Broad-spectrum intravenous antibiotics (1.5 $\mathrm{g} /$ day of metronidazole and $2 \mathrm{~g} /$ day of a thirdgeneration cephalosporin) are administered until postoperative day 5. A clear liquid diet is started on postoperative day 1 and a regular diet is started on day 3. Average urethral catheter removal was done on day 11.4 (range 5 to 15 ).

Inadvertent intraoperative rectal injuries diagnosed in the postoperative follow up were initially managed conservatively with urethral catheterization. Recto-urethral fistula was corrected with the anterior transphincteric, transanal surgical approach (ASTRA).

With this transphincteric approach the patient is placed prone in a jackknife position with the buttocks strapped apart. A perineal incision is made extending from the scrotum to the anal verge, deepened by incising all structures until excision of the fistula is performed. Layers are developed on the urinary and rectal sides of the fistula, closure of bladder is done with interrupted sutures of 2-zero polyglactin, rectal submucosa is also closed with interrupted 2-zero polyglactin sutures, and finally rectal mucosa is closed with a running 2 -zero 


\section{Table 1 - Patient characteristics.}

\begin{tabular}{|c|c|c|c|c|c|c|c|c|c|c|c|c|c|c|c|c|c|c|}
\hline $\begin{array}{c}\text { Case } \\
\mathbf{N}^{\circ}\end{array}$ & Age & ASA & BMI & $\begin{array}{l}\text { PSA } \\
\text { (ng/ } \\
\text { mL) }\end{array}$ & $\begin{array}{l}\text { Prostate } \\
\text { Surgery }\end{array}$ & $\begin{array}{r}\text { Hormone } \\
\text { Therapy }\end{array}$ & $\begin{array}{c}\text { Gleason } \\
\text { Score }\end{array}$ & $\begin{array}{c}\text { Operative } \\
\text { Time } \\
\text { (minutes) }\end{array}$ & $\begin{array}{c}\text { Rectal } \\
\text { Lesion } \\
\text { Diagnosis }\end{array}$ & $\begin{array}{c}\text { Intra- } \\
\text { operative } \\
\text { Repair }\end{array}$ & $\begin{array}{l}\text { Prostate } \\
\text { Weight } \\
\text { (grams) }\end{array}$ & $\begin{array}{l}\text { Pathological } \\
\text { Stage }\end{array}$ & Success & $\begin{array}{l}\text { Urethral S } \\
\text { Catheter }\end{array}$ & Success & $\begin{array}{l}\text { PostoperativeSt } \\
\text { Repair }\end{array}$ & uccess & Management \\
\hline 4 & 71 & 1 & 21.9 & 7 & No & No & 5 & 300 & Intraop & Yes & 50 & $\mathrm{~T} 2 \mathrm{c}$ & Yes & No & - & - & - & - \\
\hline 6 & 68 & 1 & 28 & 9 & No & No & 5 & 270 & Intraop & Yes & 59 & $\mathrm{~T} 3 \mathrm{~b}$ & No & Yes & Yes & - & - & - \\
\hline 7 & 62 & 1 & 27.8 & 4.8 & No & No & 7 & 235 & Intraop & Yes & 22 & $\mathrm{~T} 2 \mathrm{c}$ & Yes & No & - & - & - & - \\
\hline 18 & 62 & 1 & 23.7 & 6 & No & No & 6 & 180 & Intraop & Yes & 52 & $\mathrm{~T} 2 \mathrm{c}$ & Yes & No & - & - & - & - \\
\hline 22 & 63 & 1 & 29.8 & 7.8 & No & No & 6 & 150 & Missed & No & 84 & $\mathrm{~T} 2 \mathrm{a}$ & \multicolumn{2}{|c|}{$\begin{array}{l}\text { Peritonitis and } \\
\text { laparotomy }\end{array}$} & Yes & ASTRA & Yes & - \\
\hline 26 & 74 & 2 & 19.8 & 8.5 & TURP & No & 8 & 180 & Intraop & Yes & 37 & $\mathrm{~T} 3 \mathrm{~b}$ & No & Yes & Yes & - & - & - \\
\hline 28 & 64 & 2 & 24.1 & 13.7 & No & No & 6 & 300 & Missed & No & 108 & $\mathrm{~T} 2 \mathrm{c}$ & No & Yes & Yes & - & - & - \\
\hline 67 & 52 & 1 & 27.7 & 8.9 & No & No & 6 & 195 & Missed & No & 36 & $\mathrm{~T} 2 \mathrm{c}$ & \multicolumn{3}{|c|}{$\begin{array}{l}\text { Fistula } \\
\text { Urethral catheter balloon } \\
\text { extrusion through anus }\end{array}$} & $\begin{array}{l}\text { Diverting } \\
\text { colostomy and } \\
\text { primary } \\
\text { repair }\end{array}$ & No & ASTRA \\
\hline 79 & 68 & 2 & 32.6 & 37.4 & No & Yes & 9 & 240 & Intraop & Yes & 83 & $\mathrm{~T} 3 \mathrm{c}$ & No & Yes & No & ASTRA & Yes & -_ \\
\hline
\end{tabular}


polyglactin suture. The sphincter is closed with interrupted sutures; the perineal incision is then closed. No tissue grafts are used and no suction tubes are left. Oral liquids are started six hours after surgery and urethral catheter is withdrawn between postoperative day 7 and 10 .

\section{RESULTS}

Nine ( $8 \%$ ) patients were complicated by rectal injury. Six $(66.6 \%)$ out of 9 injuries were diagnosed by digital rectal examination after the prostate had been removed and the lesion was repaired intraoperatively. Three cases (33.3\%) were diagnosed postoperatively after a recto-urethral fistula was evidenced. On these 3 cases rectal digital examination had not been performed during surgery since no rectal injury was suspected and at the time routine digital rectal examination was not our practice. In all of the patients that underwent intraoperative diagnosis and repair of the rectal defect, the integrity of the repair was controlled by rectal insufflation of air in the saline filled pelvic cavity. In 4 patients injury occurred during nerve sparing radical prostatectomy. Also in 4 patients surgical preservation of bladder neck was performed. Six out of 9 injuries occurred during dissection of the posterior surface of the prostatic apex and 3 during a wide posterolateral excision.

Three $(50 \%)$ of the 6 patients with intraoperative diagnosis and repair, healed primarily without the need of colostomy. Recto-urinary fistula was evidenced by pneumaturia in the remaining $3(50 \%)$. These 3 patients were managed conservatively during 30 days with an indwelling urethral catheter. One of the patients failed conservatory management requiring secondary repair with posterior transphincteric transrectal sagital approach (ASTRA).

One of the 3 patients of postoperative diagnosis was evidenced by the extrusion of the urethral catheter through the anus on postoperative day 7 . In this patient the section of the recto-urethralis muscle was done with the Ligasure ${ }^{\mathrm{TM}}$ device. A colostomy with attempt of primary closure was done but the fistula appeared soon after. Successful definite repair using the ASTRA technique took place a month later.
On one of the other two patients, peritonitis was diagnosed on day 4 requiring laparotomy with abundant abdominal cavity saline irrigation. No fistula was evident at that moment. After 2 weeks the patient was discharged, but 15 days later he started complaining of pneumaturia. Rectal urine leakage and a $1.5 \mathrm{~cm}$ recto-urinary fistula were evident at examination. The patient underwent anterior transphincteric, transanal fistula repair without the need of a diverting colostomy. On the last patient urinary fistula was diagnosed postoperatively after pneumaturia was observed. The patient was managed conservatively with 30 days of an indwelling urethral catheter. All fistulas repaired with ASTRA evolved uneventfully. There was no perioperative mortality.

Histology showed a median postoperative Gleason score of 7 (range 5 to 9) and pathological stage was pT2a, pT2c, pT3b, pT3c in 1, 5, 2 and 1 patient respectively. Mean prostate weight was $59 \mathrm{~g}$ (range 22 to 108). There were 3 patients with positive surgical margins, 2 were apical and 1 was posterolateral.

\section{DISCUSSION}

Because radical prostatectomy is a difficult procedure, rectal laceration is always a possible complication. In the largest series of laparoscopic radical prostatectomy this injury has been reported to range from $1 \%$ to $2.4 \%$ (10-13). The incidence of rectal lesion found in our series is the highest reported $(8 \%)$ in laparoscopic radical prostatectomy, still it is within the range reported for open surgery. We believe this is because our series is a single self-taught surgeon experience with a non-standardized technique. Most of the lesions occurred during the first few surgeries while the technique was under development (cases \# $4,6,7,18,22,26,28)$.

Hoznek et al. reported 2 rectal injuries among 200 procedures (1\%) while Rassweiler et al. reported 3 rectal injuries $(1.6 \%)$ and 2 delayed recto-urethral fistulas $(1.1 \%)$ in 180 consecutive laparoscopic radical prostatectomies (10). To our knowledge our series of 110 laparoscopic extraperitoneal radical prostatectomies performed by a single surgeon in a three 
year period is one of the largest published in LatinAmerican literature. It is noteworthy to mention that the majority of injuries were observed in the first fifty patients $(77.8 \%)$. We believe that routine colostomy is not needed in the absence of a septic complication. Morbidity and costs of colostomy are well recognized.

Recent reports suggest that limited preparation of the bowel before radical prostatectomy might allow the safe closure of an associated rectal injury without colostomy $(5,14)$.

No routine preoperative bowel preparation is done and broad spectrum antibiotics are regularly administered at our institution. We believe that if a rectal lesion is to be avoided, special attention must be taken during key steps of laparoscopic radical prostatectomy. In 6 patients the rectal injury occurred when the recto-urethral muscle was sectioned from above using monopolar coagulation scissors. This is the site where rectal lesions usually occur. In the other 3 patients the rectal lesion occurred after dividing the most distal portion of the prostatic pedicles with the Ligasure $^{\mathrm{TM}}$ device. In one of these patients the division of the recto-urethralis muscle was also done with the Ligasure ${ }^{\mathrm{TM}}$ device. We believe that the rectal defect may have been temporarily sealed by the device making it undetectable and allowing the protrusion of the catheter's balloon on postoperative day 7 . To prevent rectal lesions, the apex of the prostate should be meticulously dissected by dividing the recto-urethral muscle from the posterolateral angle with cold scissors. Also, we consider paramount the adequate incision of the posterior layer of Denovillier's fascia after the dissection of both seminal vesicles has taken place. It is essential for the success of this procedure that the vesicourethral anastomosis be preformed in a watertight fashion. If a rectal laceration is done and the surgical closure is adequate, the urethral catheter must be kept in place for no less than 10 days. Primary repair can be safely done with no need for colostomy. Intraoperative identification of rectal laceration must be made in order to perform primary repair and avoid diverting colostomy. We concur with recent reports in that early postoperative care such as antibiotic therapy, low fiber diet and anal dilation may help the healing of a rectal injury (1517).
However, primary repair can fail and a rectourinary fistula may develop. Minimally invasive perineal approaches can be used such as ASTRA, which allows fistula resection and adequate closure $(18,19)$. This approach was first described by Gecelter (18) in 1973 and reproduced at our institution only changing the forced lithotomy position for a jack-knife position (20).

However, like many authors we believe that the best treatment of fistula is injury prevention with careful dissection of the posterior prostatic planes.

In our current experience of over 300 extraperitoneal laparoscopic radical prostatectomies, no rectal lesion has occurred in the last 150 cases. This can be explained by the systematization of the technique and the acquired expertise of the surgeons who performed it.

\section{CONCLUSIONS}

Rectal injury during laparoscopic extraperitoneal radical prostatectomy is a dreaded complication. It can be managed intraoperatively or by a minimally invasive procedure without the need of colostomy. Early diagnose and rectal wall closure in two layers is essential for successful repair. The best treatment of fistula is injury prevention with careful dissection of the posterior prostatic planes. Because laparoscopic radical prostatectomy is a challenging procedure and is associated with a very flat learning curve, the incidence of rectal injuries is prone to diminish with experience.

\section{CONFLICT OF INTEREST}

None declared.

\section{REFERENCES}

1. Schuessler WW, Kavoussi LR, Clayman RV, Vancaille $\mathrm{T}$ : Laparoscopic radical prostatectomy: initial case report. J Urol. 1992; 147: 246A. 
2. Schuessler WW, Schulam PG, Clayman RV, Kavoussi LR: Laparoscopic radical prostatectomy: initial shortterm experience. Urology. 1997; 50: 854-7.

3. Bollens R, Vanden Bossche M, Roumeguere T, Damoun A, Ekane S, et al.: Extraperitoneal laparoscopic radical prostatectomy. Results after 50 cases. Eur Urol. 2001; 40: 65-9.

4. Harpster LE, Rommel FM, Sieber PR, Breslin JA, Agusta VE, Huffnagle HW, et al.: The incidence and management of rectal injury associated with radical prostatectomy in a community based urology practice. J Urol. 1995; 154: 1435-8.

5. Katz R, Borkowski T, Hoznek A, Salomon L, de la Taille A, Abbou CC: Operative management of rectal injuries during laparoscopic radical prostatectomy. Urology. 2003; 62: 310-3.

6. McLaren RH, Barrett DM, Zincke H: Rectal injury occurring at radical retropubic prostatectomy for prostate cancer: etiology and treatment. Urology. 1993; 42: 401-5.

7. Leandri P, Rossignol G, Gautier JR, Ramon J: Radical retropubic prostatectomy: morbidity and quality of life. Experience with 620 consecutive cases. J Urol. 1992; 147: 883-7.

8. Igel TC, Barrett DM, Segura JW, Benson RC Jr, Rife CC: Perioperative and postoperative complications from bilateral pelvic lymphadenectomy and radical retropubic prostatectomy. J Urol. 1987; 137: 1189-91.

9. Borland RN, Walsh PC: The management of rectal injury during radical retropubic prostatectomy. J Urol. 1992; 147: 905-7.

10. Hoznek A, Salomon L, Olsson LE, Antiphon P, Saint F, Cicco A, et al.: Laparoscopic radical prostatectomy. The Creteil experience. Eur Urol. 2001; 40: 38-45.

11. Rassweiler J, Sentker L, Seemann O, Hatzinger M, Stock C, Frede T: Heilbronn laparoscopic radical prostatectomy. Technique and results after 100 cases. Eur Urol. 2001; 40: 54-64.

12. Turk I, Deger S, Winkelmann B, Schonberger B, Loening SA: Laparoscopic radical prostatectomy. Technical aspects and experience with 125 cases. Eur Urol. 2001; 40: 46-52; discussion 53.

13. Elder JS, Gibbons RP, Correa RJ Jr, Brannen GE: Morbidity of radical perineal prostatectomy following transurethral resection of the prostate. J Urol. 1984; 132: 55-7.

14. Guillonneau B, Gupta R, El Fettouh H, Cathelineau $\mathrm{X}$, Baumert H, Vallancien G: Laparoscopic [correction of laproscopic] management of rectal injury during laparoscopic [correction of laproscopic] radical prostatectomy. J Urol. 2003; 169: 1694-6.

15. Renschler TD, Middleton RG: 30 years of experience with York-Mason repair of recto-urinary fistulas. J Urol. 2003; 170: 1222-5; discussion 1225.

16. Venable DD: Modification of the anterior perineal transanorectal approach for complicated prostatic urethrorectal fistula repair. J Urol. 1989; 142: 3814.

17. Noldus J, Fernandez S, Huland H: Rectourinary fistula repair using the Latzko technique. J Urol. 1999; 161: 1518-20.

18. Gecelter L: Anterior transanorectal approach for posterior urethral strictures. S Afr J Surg. 1972; 10: 189-93.

19. Culkin DJ, Ramsey CE: Urethrorectal fistula: transanal, transsphincteric approach with locally based pedicle interposition flaps. J Urol. 2003; 169: 2181-3.

20. Castillo, O., Bodden, M., Vitagliano, G., Gomez, R.: Anterior transanal, transsphincteric sagital approach for fistula repair secondary to laparoscopic radical prostatectomy: a simple and effective technique (Submitted).

\section{Correspondence address:}

Dr. Octavio Castillo

Av. Santa Maria 500

Providencia, Santiago, Chile

E-mail: octaviocastillo@ vtr.net 